\title{
MOTION PREDICTION OF CATAMARAN WITH A SEMI- SUBMERSIBLE BOW IN WAVE
}

\author{
Hanbing Sun, Ph.D. \\ Fengmei Jing, Ph.D. \\ Yi Jiang, M.Sc. \\ Jin Zou, Prof. \\ Jiayuan Zhuang, Ph.D. \\ Weijia Ma, Ph.D. \\ Harbin Engineering University, China
}

\begin{abstract}
Compared with standard vessels, a slender catamaran with a semi-submerged bow (SSB) demonstrates superior seakeeping performance. To predict the motion of an SSB catamaran, computational fluid dynamics methods are adopted in this study and results are validated through small-scale model tests. The pitch, heave, and vertical acceleration are calculated at various wavelengths and speeds. Based on the overset grid and motion region methods, this study obtains the motion responses of an SSB catamaran in regular head waves. The results of the numerical studies are validated with the experimental data and show that the overset grid method is more accurate in predicting the motion of an SSB catamaran; the errors can be controlled within 20\%. The movement data in regular waves shows that at a constant speed, the motion response initially increases and then decreases with increasing wavelength. This motion response peak is due to the encountering frequency being close to the natural frequency. Under identical sea conditions, the motion response increases with the increasing Froude number. The motion prediction results, that derive from a shortterm irregular sea state, show that there is an optimal speed range that can effectively reduce the amplitude of motion.
\end{abstract}

Keywords: SSB catamaran; model test; overset grid; motion region; motion response

\section{INTRODUCTION}

Improving a ship's seakeeping performance and enhancing its navigational performance under stormy wave conditions are prominent research topics in the marine industry. This has given rise to a variety of high-performance vehicle and roll stabilisation technologies. The SSB catamaran, which combines the characteristics of a slender catamaran and an SSB, provides advantages such as excellent seakeeping performance, good stability, comfort, shallow draft, and a spacious deck. Because the composite hull has broad development prospects, it is necessary to predict its seakeeping performance.

The motion response of a vessel in waves can be predicted by using either the potential flow or viscous flow method. Potential flow theory is currently widely used to calculate ship motions and wave loads [1]. However, because the viscous damping force of an SSB is much greater than that of a conventional vessel in the same motion state, the effect of SSB viscous drag on pitching stabilisation cannot be reflected using this method. Therefore, the seakeeping performance of these complex vessels must be experimentally calculated. Hang has studied methods suited for predicting the seakeeping performance of vessels that use an SSB by using STF slice theory [2]. Zhao's study of a wave-piercing SSB catamaran showed an improved seakeeping comprehensive index and significantly reduced pitching [3]. Cai conducted a model test and sea trial of a full-scale 450-ton ship. The results indicated that the composite monomer ship displayed excellent seakeeping performance; this assembly was able to significantly inhibit the longitudinal movement of the ship [4-5]. A number of studies have used theoretical calculations and model tests on a newly developed deep-V ship with a composite monomer hull. The results showed that this assembly significantly improved seakeeping performance [6-8]. Gao installed a semi-submersible hull on a wavepiercing catamaran in order to decrease pitching; the results showed, that the seakeeping performance of the ship was significantly enhanced [9]. Silva and Soares described a timedomain non-linear strip theory model of ship motions in six degrees-of-freedom and predicted the parametric rolling of an SSB containership [10].

This study analysed the seakeeping performance of a slender SSB catamaran under regular wave conditions by means of small-scale model testing and numerical simulation. Computational fluid dynamics (CFD) software 
STAR-CCM+ was used for the simulation based on a six degrees-of-freedom rigid body equation and overset grid technology. By comparing the numerical and experimental results, a numerical method with a short cycle and low cost can be obtained to effectively improve the efficiency of ship optimization.

\section{NUMERICAL SIMULATION METHOD}

\section{GOVERNING EQUATIONS}

Incompressible Newtonian fluid motion conforms to both the continuity and the momentum conservation equations:

$$
\begin{gathered}
\frac{\partial p}{\partial t}+\frac{\partial\left(\rho u_{i}\right)}{\partial x_{i}}=0 \\
\frac{\partial\left(\rho u_{i}\right)}{\partial t}+\frac{\partial}{\partial x_{i}}\left(\rho u_{i} u_{j}\right)= \\
-\frac{\partial p}{\partial x_{i}}+\frac{\partial}{\partial x_{j}}\left(\mu \frac{\partial u_{i}}{\partial x_{j}}-\rho \overline{u_{i}^{\prime} u_{j}^{\prime}}\right)+S_{i}
\end{gathered}
$$

where $u_{i}$ and $u_{j}$ are the time mean values of velocity, $i, j=1,2,3$; whereas $p$ is the time mean value of pressure, $\rho$ is the fluid density, $\mu$ is the dynamic viscosity coefficient, $\rho \overline{u_{i}^{\prime} u_{j}^{\prime}}$ is the Reynolds stress, and $\mathrm{S}_{\mathrm{i}}$ is the generalized source terms of momentum equation.

\section{TURBULENCE MODEL}

The selection of a turbulence model has a dramatic influence on the hydrodynamic calculation. There are four turbulence models widely applied in engineering calculations: standard $\mathrm{k}-\varepsilon$, RNG k- $\varepsilon$, standard k- $\omega$, and SST k- $\omega$. The introduction of these turbulence models can be found in numerous references. After a comprehensive considering of the computational comparisons of these four common turbulence models in references [11] and [12], this paper uses the SST k- $\omega$ turbulence model because it can simulate the complex flow problems with flow separation and strong adverse pressure gradients. The equation is written as follows:

$$
\begin{gathered}
\frac{\partial(\rho k)}{\partial t}+\frac{\partial}{\partial x_{i}}\left(\rho k u_{i}\right)= \\
\frac{\partial}{\partial x_{i}}\left(\Gamma_{k} \frac{\partial k}{\partial x_{i}}\right)+G_{k}-Y_{k} \\
\frac{\partial(\rho \omega)}{\partial t}+\frac{\partial}{\partial x_{i}}\left(\rho \omega u_{i}\right)= \\
\frac{\partial}{\partial x_{i}}\left(\Gamma_{\omega} \frac{\partial \omega}{\partial x_{i}}\right)+G_{\omega}-Y_{\omega}+D \omega
\end{gathered}
$$

where $G_{k}$ and $G_{\omega}$ are the turbulent kinetic energies caused by the mean velocity gradient, and $\mathrm{Y}_{\mathrm{k}}$ and $\mathrm{Y}_{\omega}$ are the turbulence dissipation rates for $\mathrm{k}$ and $\omega$, respectively.

\section{TREATMENT OF FREE SURFACE}

The VOF method is adopted to capture the free surface. For a given computational domain $\mathrm{V}$, Fluid 1 is in domain $\mathrm{V}_{1}$, and Fluid 2 is in domain $\mathrm{V}_{2}$. The function is defined as follows:

$$
\boldsymbol{\alpha}(\mathbf{x}, t)=\left\{\begin{array}{l}
1, \mathbf{x} \in \mathrm{V}_{1} \\
0, \mathbf{x} \in \mathrm{V}_{2}
\end{array}\right.
$$

For a flow field composed of two incompatible fluids, $\alpha(x, t)$ is in accordance with:

$$
\frac{\partial \boldsymbol{\alpha}}{\partial t}+\mathbf{U} \cdot \nabla \boldsymbol{\alpha}=0
$$

where $\mathrm{U}=(\mathrm{u}, \mathrm{v}, \mathrm{w})$ is the fluid velocity field, and the VOF function $\mathrm{C}_{\mathrm{ijk}}$ is defined as the integral in the grid unit of $a(x, t)$ divided by unit volume, i.e.,

$$
\mathrm{C}_{i j k}=\frac{1}{\Delta \mathrm{V}_{i j k}} \int_{I_{i j k}} \boldsymbol{\alpha}(\mathbf{x}, t) d \mathrm{~V}
$$

$\mathrm{C}_{\mathrm{ijk}}$ is in accord with $(\partial \mathrm{C} / \partial \mathrm{t})+\mathrm{U} \cdot \nabla \mathrm{C}=0$. When $\mathrm{C}=1$, the grid is filled with Fluid 1 . When $\mathrm{C}=0$, the grid excludes Fluid 1 . When $0<\mathrm{C}<1$, the grid contains free surface.

\section{GENERATING WAVE METHOD}

The wave module of CFD software STAR-CCM+ is used to generate regular sinusoidal propagating waves in an infinite water depth. According to linear theory, the $\mathrm{x}$ and $\mathrm{z}$-components of the velocity are given by the following equations:

$$
\begin{gathered}
v_{x}=\omega \zeta_{a} e^{k z} \sin (\omega t-k x) \\
v_{z}=\omega \zeta_{a} e^{k z} \cos (\omega t-k x) \\
\zeta=\zeta_{a} \sin (\omega t-k x)
\end{gathered}
$$

where $\zeta_{a}$ is the wave amplitude, $\omega=2 \pi / T$ is the wave frequency, $k=2 \pi / \lambda$ is the wave number, $T$ is the wave period, $\lambda$ is the wavelength, and $x$ is the direction of wave propagation. $\mathrm{z}$ is positive when upward, with $\mathrm{z}=0$ the mean water level.

\section{THE COMPUTATIONAL DOMAIN AND BOUNDARY CONDITIONS}

A computational domain is established to simulate the fluid around the SSB catamaran. Dimensions are presented in Fig. 1 which consider both boundary interference and computational cost. In order to reduce interference from the sides of the computational domain, the inlet of the computational domain is defined as one ship length from the bow, the outlet is defined as three ship lengths from the stern, and the side is defined as one ship length from the 
hull. To improve computational efficiency, only half of the hull is modelled and the longitudinal section is selected as the symmetry plane.

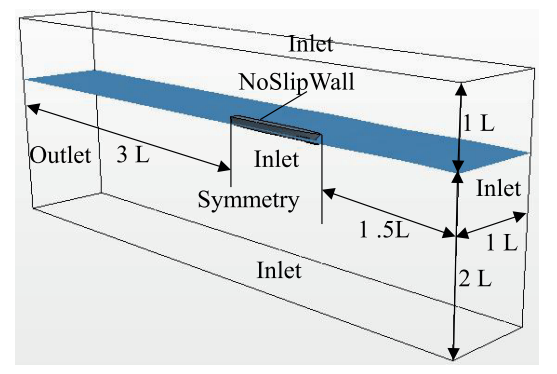

Fig. 1. Computational domain of the SSB catamaran

The head and side surfaces of the computational domain are set as the velocity inlet, the rear surface is set as the pressure outlet, and the hull surface is seen as a rigid wall.

\section{THE MESH GENERATION AND MOTION SIMULATION}

The resolution of the mesh has a significant influence on computational accuracy; thus, trimmed mesh is used to discretize the entire computational domain. In order to ensure accurate results, a boundary layer mesh of 3 near the hull and a surface mesh size of $0.003 \mathrm{~L}$ are selected; the free surface is also encrypted.

Overset grid and motion region techniques are applied to simulate the motion response of an SSB catamaran in waves.

In the overset grid method, the grid covering the computational domain is designated as the main grid, and the local grid containing the moving objects is designated as the slave grid. The outermost grid nodes of the subordinate parts can communicate with the main grid through interpolation. To ensure a fitted mesh division of complex shapes, the flow area is divided into sub-regions with simple geometric borders. Several researchers [13-15] have described overset grid technology in detail. Previous studies on mono-hull, catamaran, and trimaran vessels have shown, that the flow around ships with free surfaces can be effectively simulated with the overset grid method [15].

In the motion region method, the entire computational region is handled as a single entity. Momentum equations are discretised with a finite volume method in the time domain, and the non-steady solution is solved using a separation type solver. The RANS equation and the six-degree of freedom motion equation are calculated simultaneously to simulate the motion response of an SSB catamaran. Fig. 2 shows the views of the overset mesh and the motion region mesh.
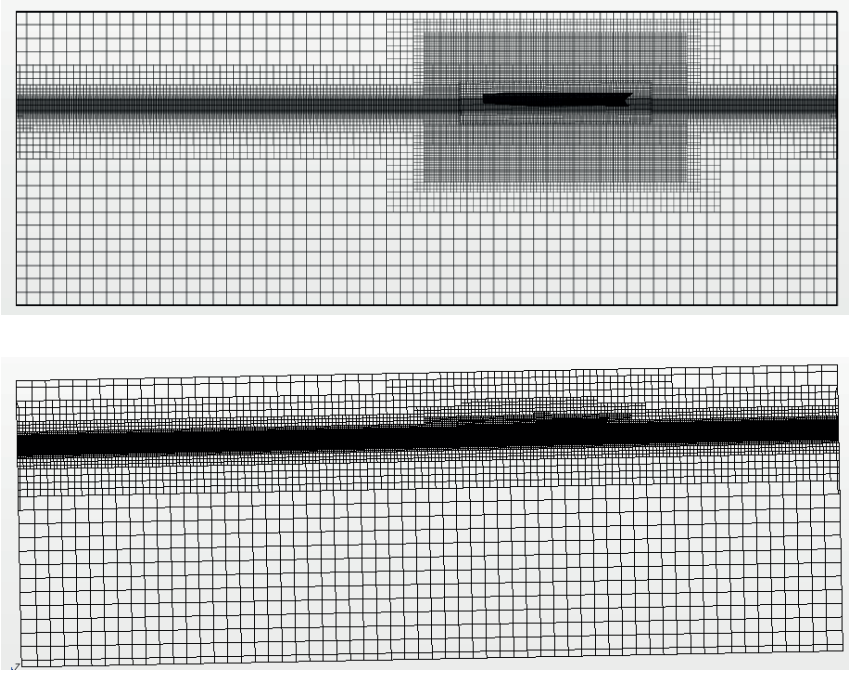

Fig. 2. Schemes of the SSB catamaran (a) Overset grid scheme (b) Motion region scheme

\section{EXPERIMENTAL RESULTS}

\section{DESCRIPTION OF THE MODEL}

A numerical simulation and model test of an SSB catamaran were carried out and the results were compared. The main dimensions are shown in Table 1 and the moulded lines are shown in Fig. 3.

Table 1. Main particulars of model

\begin{tabular}{|c|c|}
\hline Principal particular & value \\
\hline Length $\left(L_{m}\right)$, in $[\mathrm{mm}]:$ & 4480 \\
\hline Beam $(B)$, in $[\mathrm{mm}]:$ & 956 \\
\hline Demihull spacing $(\mathrm{K})$, in $[\mathrm{mm}]:$ & 715 \\
\hline Displacement $(\Delta)$, in $[\mathrm{kg}]:$ & 250 \\
\hline Draft $\left(T_{D W L}\right)$, in $[\mathrm{mm}]:$ & 152 \\
\hline Water line length $\left(L_{W L}\right)$, in $[\mathrm{mm}]:$ & 4224 \\
\hline $\begin{array}{c}\text { Longitudinal center of gravity }\left(x_{g}\right), \text { in } \\
{[\mathrm{mm}] \text { : }}\end{array}$ & 1980 \\
\hline Height center of gravity $\left(z_{g}\right)$, in $[\mathrm{mm}]:$ & 149 \\
\hline Longitudinal rotation inertia, in $\left[\mathrm{kg} \cdot \mathrm{m}^{2}\right]$ & 230 \\
\hline
\end{tabular}

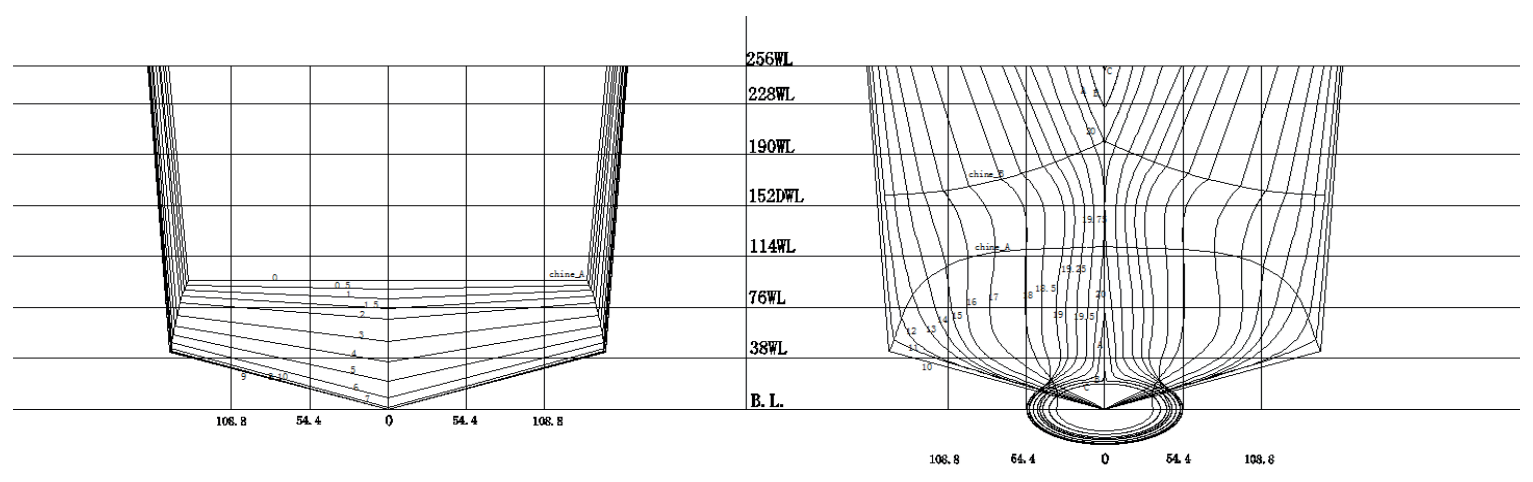

Fig. 3. Model ship lines 


\section{EXPERIMENTAL SETUP}

Model tests were carried out at Harbin Engineering University, in a $108 \times 7 \mathrm{~m}$ basin with a water depth of up to $3.5 \mathrm{~m}$. The model was comprised of fiberglass composite materials. The model tests used the free lambent method to measure resistance, pitch, heave, and the amidships aft bow acceleration parameters. The DHDAS_5920 dynamic signal acquisition and analysis system was used for data acquisition. Fig. 4 shows the experimental setup, and Fig. 5 shows the model in the tank.

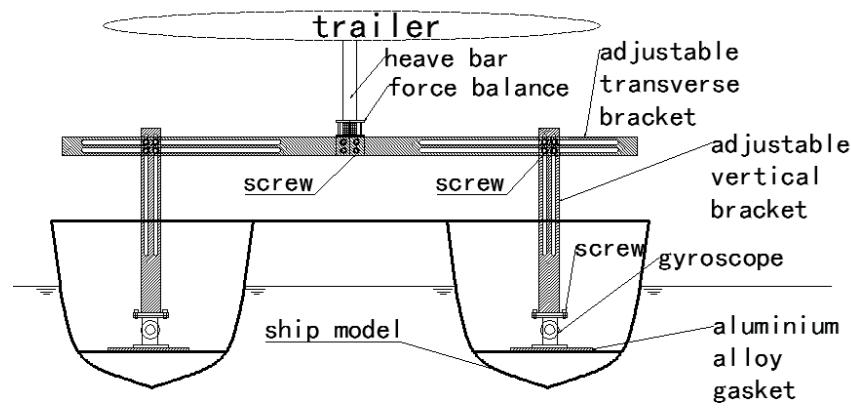

Fig. 4. Sketch of model test scheme

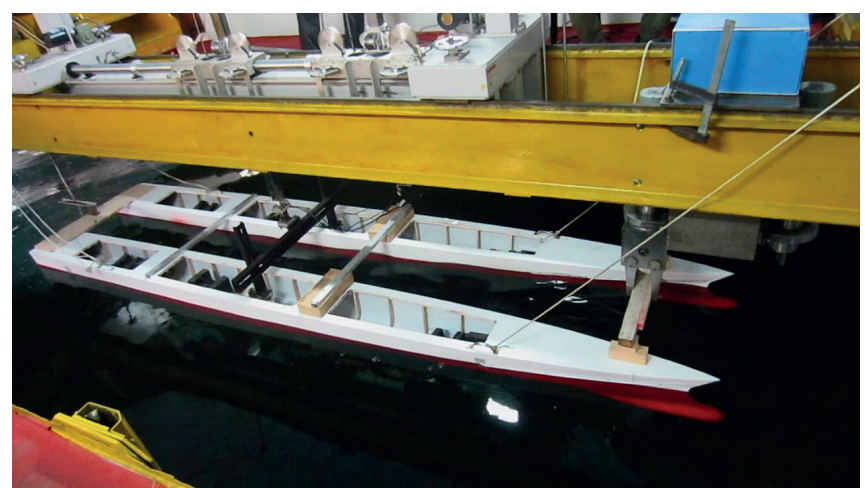

Fig. 5. Model in the tower tank

\section{COMPARISON OF NUMERICAL SIMULATIONS AND EXPERIMENTAL RESULTS}

Simulations of the SSB catamaran in regular waves for a head sea are computed by two numerical schemes: the overset grid and motion region methods. The inputs are a wave height $/ \mathrm{H}_{\mathrm{a}}$ of $0.04 \mathrm{~m}$, wavelengths $/ \lambda$ of $2.24,3.14,3.59$, $4.03,4.48,4.93,5.38,5.83,6.72,7.84 \mathrm{~m}$, and Froude numbers $/ \mathrm{F}_{\mathrm{r}}$ of 0.33 and $0.44, F_{r}=v / \sqrt{g L_{m}}$, a time step of $0.001 \mathrm{~s}$.

The calculated results are compared with the experimental values in terms of the amplitude-frequency response functions of heave, pitch, and acceleration, as shown in Figs. 6 - 11. The abscissa in each graph is the encountered frequency $/ \omega_{\mathrm{e}}$, in $\mathrm{rad} / \mathrm{s}$, whereas the ordinate in each case is the amplitudefrequency response function. To assess heave, the ordinate is the amplitude of the heave/za to the wave amplitude $/ \zeta_{\mathrm{a}}$ ratio, $\mathrm{za} / \zeta_{\mathrm{a}}$. For pitch, it is the amplitude of the pitch $/ \theta_{\mathrm{a}}$ divided by the wave amplitude $/ \zeta_{a}$ multiplied by the wave number $/ \mathrm{k}$, $\theta_{a} / k \zeta_{2}$. For acceleration, it is the amplitude of the acceleration at the centre of gravity/am multiplied by the model length/ $\mathrm{L}_{\mathrm{m}}$, which is divided by the gravitational acceleration constant/g multiplied by the wave amplitude $/ \zeta_{\mathrm{a}}$ ratio, amLm/g $\zeta_{\mathrm{a}}$.

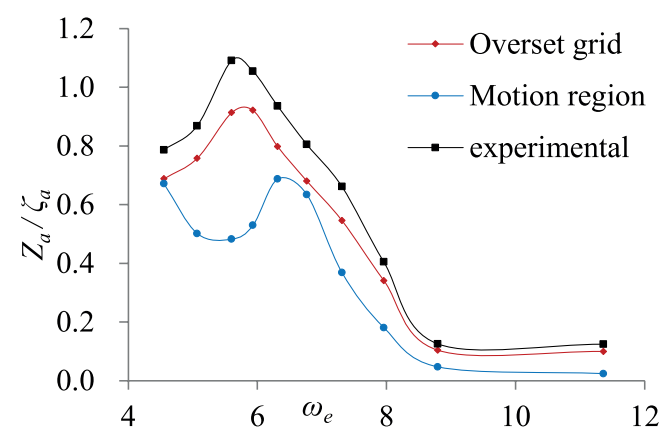

Fig. 6. Heave response curve, $F_{r}=0.33$

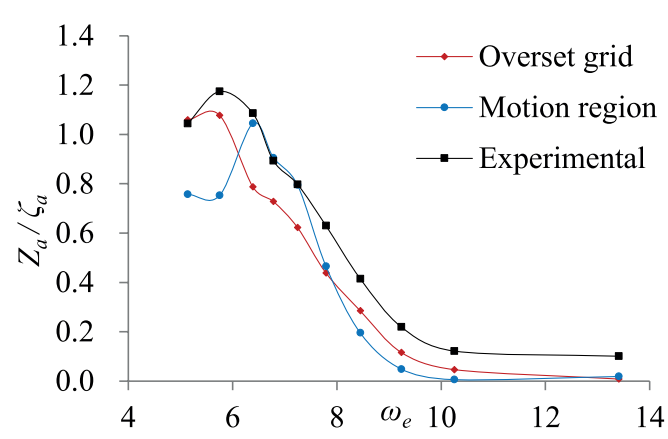

Fig. 7. Heave response curve, $F_{r}=0.44$

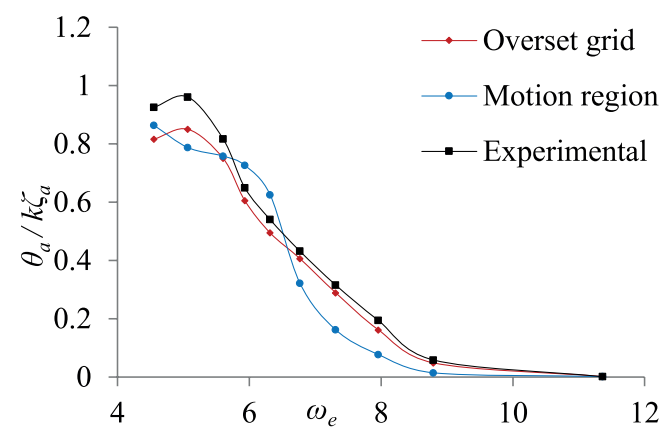

Fig. 8. Pitch response curve, $F_{r}=0.33$

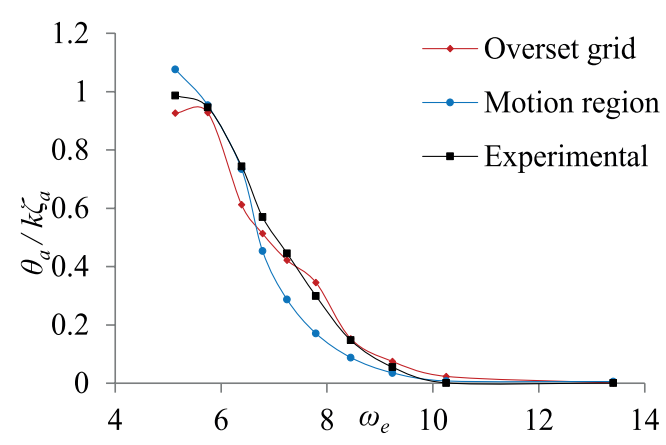

Fig. 9. Pitch response curve, $F_{r}=0.44$ 


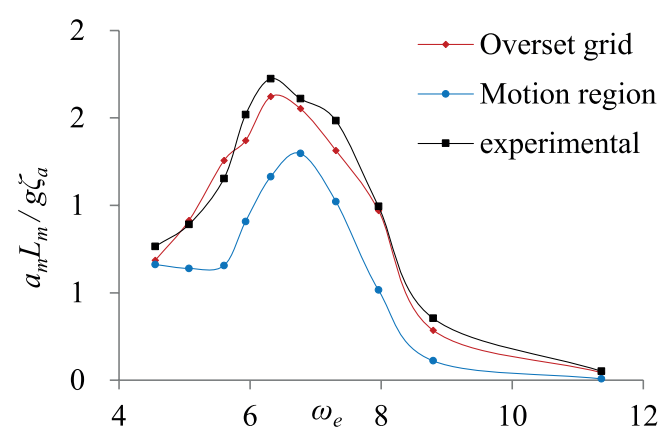

Fig. 10. Vertical acceleration response curve, $F_{r}=0.33$

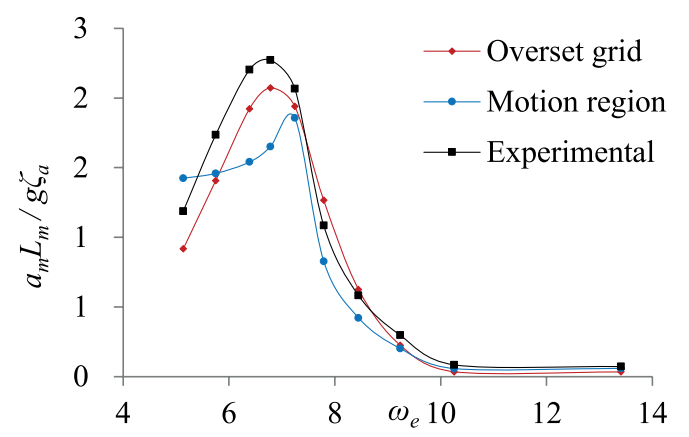

Fig. 11. Vertical acceleration response curve, $F_{r}=0.44$

Figs. 6-11 indicate that the results of the two numerical calculations are consistent with the trends in experimental values. Thus, these numerical methods are capable of analysing and predicting the motion response of the SSB catamaran under regular wave conditions in a head sea. However, the results based on overset grid technology are more accurate than those based on motion region technology.

A detailed analysis of the calculation results for a wavelength of $6.72 \mathrm{~m}$ and Froude number of 0.33 is carried out. This wavelength is approximately 1.5 times $\mathrm{L}_{\mathrm{m}}$, which is generally believed to be the movement response peak.

Fig. 12 shows the test image of the model ship and the free surface waveform obtained by numerical calculation.

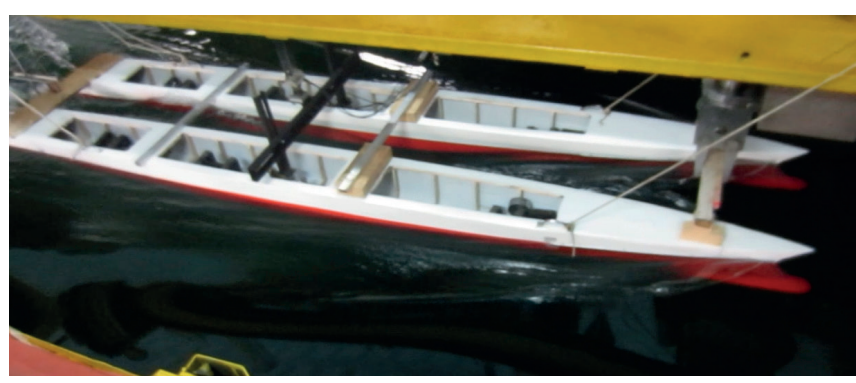

Fig. 12. Free surface waveform (a) Model test presentation
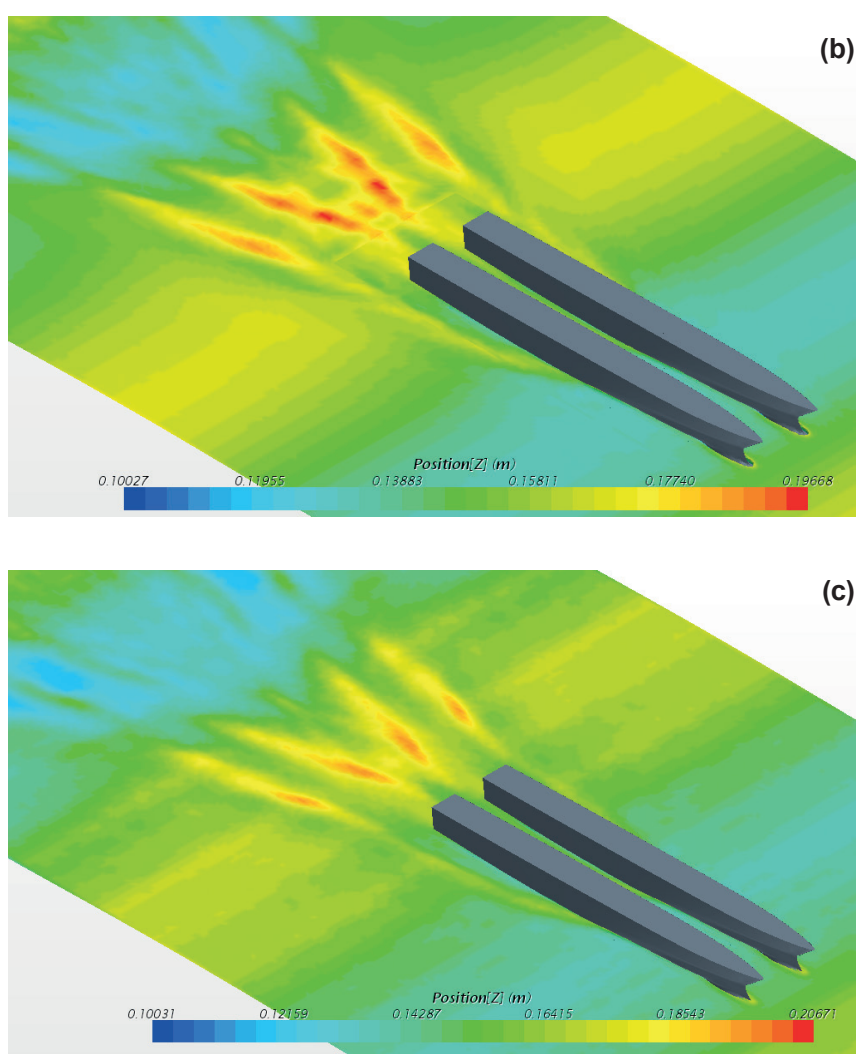

Fig. 12. Free surface waveform: (b) Overset grid method, (c) Motion region method

The time histories of the resistance and the average value are shown in Fig. 13. The time histories of the sinkage, trim angle, and vertical acceleration are shown in Fig. 14-16. The element number, computational time and error of resistance are summarized in Table 2.

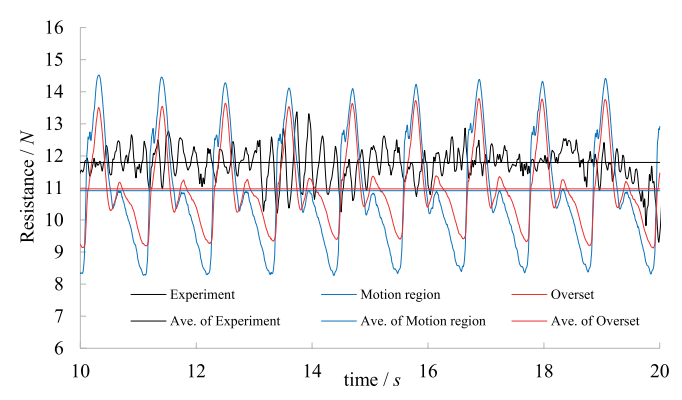

Fig. 13. Time histories and the average value of resistance

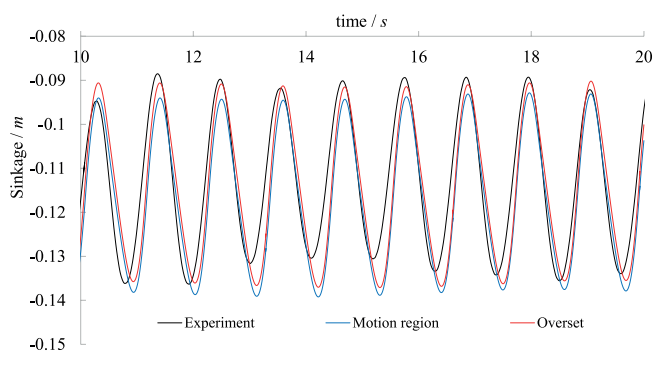

Fig. 14. Time histories of sinkage 


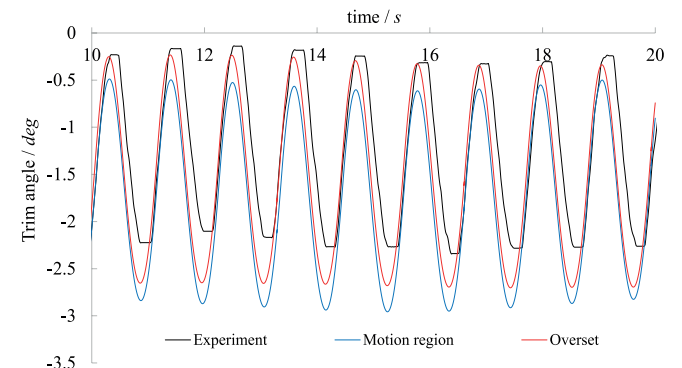

Fig. 15. Time histories of trim angle

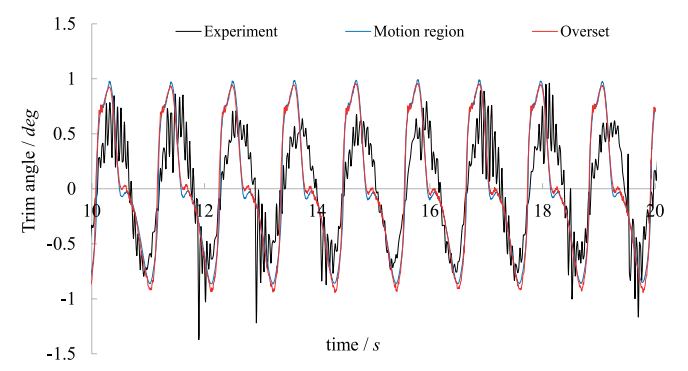

Fig. 16. Time histories of vertical acceleration

Tab. 2. Comparison of the schemes

\begin{tabular}{|c|c|c|}
\hline Schemes & $\begin{array}{c}\text { Overset grid } \\
\text { method }\end{array}$ & $\begin{array}{c}\text { Motion region } \\
\text { method }\end{array}$ \\
\hline $\begin{array}{c}\text { Element } \\
\text { number }\end{array}$ & $1.37 \times 10^{6}$ & $1.22 \times 10^{6}$ \\
\hline $\begin{array}{c}\text { Computational } \\
\text { time (hour) }\end{array}$ & 35 & 23 \\
\hline $\begin{array}{c}\text { Error of } \\
\text { resistance } \\
(\%)\end{array}$ & 6.5 & 7.4 \\
\hline
\end{tabular}

Considering both computational accuracy and computational time, overset grid method is adopted to predict the motion response of an SSB catamaran in a wave.

\section{PREDICTION OF SEAKEEPING PERFORMANCE}

It is evident from the test data, that the overset grid method is more accurate in the numerical simulation of complex hulls. The method is able to effectively forecast the seakeeping performance of an SSB catamaran, with errors of approximately $10 \%$ that do not exceed $20 \%$. This study uses the overset grid method to calculate the motion response of an SSB catamaran at speeds of $0.727,1.45,1.75$, and $2.62 \mathrm{~m} / \mathrm{s}$, with an amplitude of $0.02 \mathrm{~m}$ and wavelengths of 2.24, 3.14, $3.59,4.03,4.48,4.93,5.38,5.83,6.72$, and $7.84 \mathrm{~m}$. The results are shown in Figs. 17-18 and illustrate, that the amplitudefrequency response functions of pitch and heave increase as the encountered frequency decreases at the same speed. This is due to the motion response of the ship decreasing as the wavelength decreases. The amplitude-frequency response functions of pitch and heave peak at a Froude number of 0.4, which is due to the wavelength of $5.83 \mathrm{~m}$ being approximately 1.3 times the model length. The natural pitching and heaving periods were similar to the encountered period, resulting in the emergence of a resonance phenomenon. Furthermore, the motion response of the ship increases as the speed increases at the same wavelength.
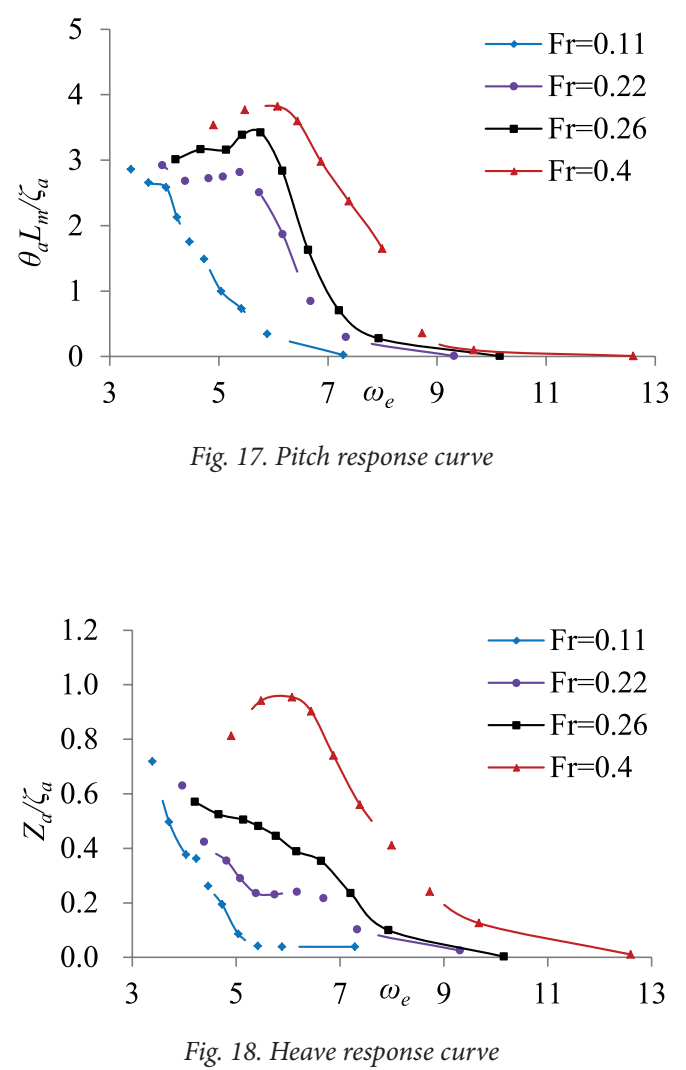

In calculating the numerical results, this study uses typical sea states according to the ITTC two-parameter spectrum, proposed by the International Ship Model Basin Conference [16]. The seakeeping performance of a full-scale $56 \mathrm{~m}$ ship in a level 2-6 sea state is shown in Figs. 19-20, where the reduced scale ratio is 12.5 . The abscissa in both cases is the sea state, whereas the ordinate is significant value of pitch angle $\left(\theta_{1 / 3}\right.$, measured in deg) and sinkage $\left(\mathrm{z}_{1 / 3}\right.$, measured in $\left.\mathrm{m}\right)$.

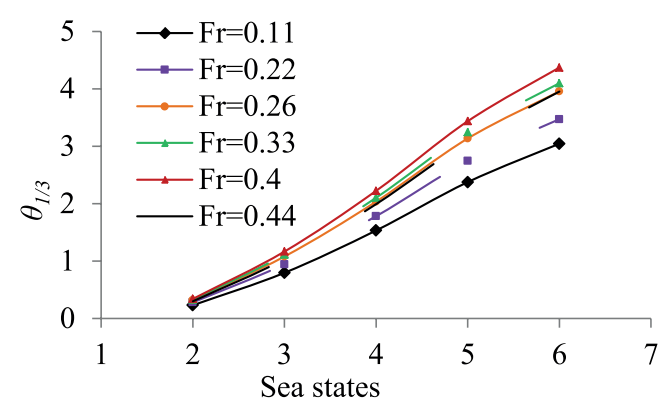

Fig. 19. Significant pitch 


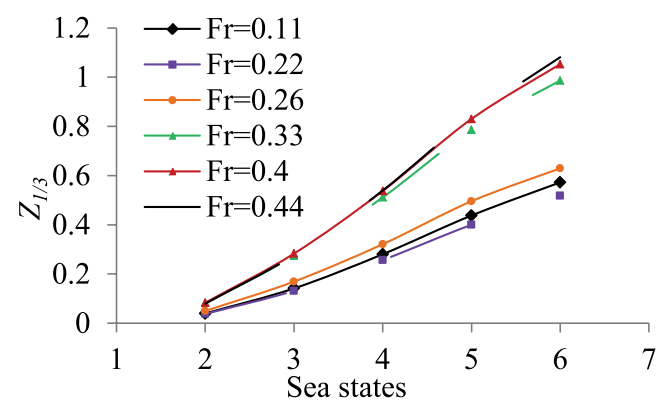

Fig. 20. Significant heave

Figs. 19-20 show that the significant values of pitching and heaving increase as the sea state increases at a constant speed. The significant values of heaving increase as the speeds increase at a constant sea state, whereas the added amplitudes decrease. The significant values of pitching have a downward trend at $\mathrm{F}_{\mathrm{r}}=0.44$ because the encountered period deviates from the natural pitching period as the speeds increase, and the resonance region is thus avoided.

\section{CONCLUSIONS}

The results of this study show, that the motion response of an SSB catamaran under regular wave conditions can be accurately predicted by the use of an overset grid based on viscous flow numerical calculation theory. Based on the calculation of the amplitude of movement under various sea conditions, the following conclusions can be obtained.

A comparison of the results of the overset grid, the motion region methods, and the experimental data of the ship model shows, that the results obtained by the two numerical methods have similar trends. However, the overset grid is more accurate in the prediction of the motion response of an SSB catamaran under regular wave conditions when heading into the wave. Thus, the seakeeping performance of an SSB catamaran can be effectively forecast.

The motion response of an SSB catamaran under regular wave conditions in a heading wave has been simulated, the frequency response function has been solved, and the trends of heave and pitch motion at various speeds have been analysed. The results show, that the motion response of an SSB catamaran decreases with an increase in encounter frequency. However, a resonance phenomenon can occur when the encounter period approaches the natural period of heave and pitch of the ship.

The pitching and heaving motion of a $56 \mathrm{~m} \mathrm{SSB}$ catamaran was calculated by using the ITTC two-parameter spectrum method, and pitch and heave amplitudes at various sea levels were obtained. The results show, that the extent of heave amplitude increase is reduced as the speed increases; the pitching amplitude shows a downtrend as $\mathrm{F}_{\mathrm{r}}$ approaches 0.44 . When an SSB catamaran is sailing in a head sea, there is an optimal speed range at which resonance can be avoided and the amplitude of movement can be reduced.

\section{ACKNOWLEDGMENTS}

This work was supported by the National Natural Science Foundation of China (Grant Nos. 51409069, 51409054 and 51509055), the China Postdoctoral Science Foundation (2015 M571397) and the Fundamental Research Funds for the Central Universities (Grant No. HEUCF150118).

\section{BIBLIOGRAPHY}

1. ODD M. Faltinsen. Hydrodynamics of high-speed marine vehicles[M]. Cambridge: Cambridge University Press, 2005.

2. Dingliang Huang, Zhidan Ai, Dianlu Xing. Research on Seakeeping Performance of Semi-Submerged Bow Ship, Shipbuilding of China, 1992, 3(1):40-46.

3. Lian'en Zhao, Yi He, Jide Li, et al. A Study on Motion Performance of Multi-hull Wave Piercer, Shipbuilding of China, 1997(4): 20-28.

4. Xingong Cai, Jide Li, Jianfang Wang. Experimental Study on Built-up Stabilizing Appendage, Shipbuilding of China, 2003, 44(3): 51- 57.

5. Xingong Cai, Jide Li. Comparative Sea Trial of a Highspeed Ship with Built-up Stabilizing Appendage, Shipbuilding of China, 2003, 44(4): 13- 18.

6. Jide Li, Heng Zhang, Xiaodong Zhao. Experimental study on $4000 \mathrm{t}$ deep- $\mathrm{V}$ hybrid monohull, Journal of Ship Mechanics, 2008, 12(5): 709-715.

7. Shuzheng Sun, Jide Li, Xiaodong Zhao, et al. Research on Longitudinal Motion Performance of Deep-V Hybrid Mono-hull, Ship Ocean Engineerin, 2009, 38(5): 54-57.

8. Xujie Wang, Shuzheng Sun, Xiaodong Zhao, et al. Research on model test of thousands-tons class high seakeeping performance hybrid monohull, Journal of Ship Mechanics, 2011, 15(4): 343-349.

9. Ni Gao, Shuzheng Sun, Zaibai Qin, et al. Model test research on WPC with semi-submerged appendage, J. Huazhong Univ. of Sci. Tech. (Natural Science Edition), 2013, 41(3): 97-100.

10. SRE Silva, CG Soares. Prediction of parametric rolling in waves with a time domain non-linear strip theory model, Ocean Engineering, 72 (2013): 453-469.

11. Rui Deng. Numerical Research on Influence of the Interceptor on Catamaran Hydrodynamic Performances [D], Harbin Engineering University, 2010. 
12. Li Wang. The Applicability Analysis of the Usually Applied Turbulence Models and the Numerical Simulation of the Flow Around a Foil using VOF Method [D], Huazhong University of Science and Technology, 2007.

13. Shulian Tian. Investigation of Overset Unstructured Grids Algorithm [D], Nanjing University of Aeronautics and Astronautics, 2008.

14. Jingxin Liu, HU Akay, Akin Ecer, et al. Flows Around Moving Bodies Using a Dynamic Unstructured Oversetgrid Method, International Journal of Computational Fluid Dynamics, 2010, 24(6): 187-200.

15. Faming Zhao, Chengjun Gao, Qiong Xia. Overlap grid research on the application of ship CFD, Journal of Ship Mechanics, 2011, 15(4): 332-341.

16. Jide Li. Seakeeping Performance of Ship [M], Harbin Engineering University Press, 2007.

\section{CONTACT WITH THE AUTHORS}

\author{
Fengmei Jing \\ Corresponding author
}

\author{
College of Shipbuilding Engineering \\ Harbin Engineering University \\ Nan tong street Harbin \\ HLJ \\ P. R. CHINA \\ e-mail: jingfengmei@hrbeu.edu.cn
}

